\title{
HOJE EM DIA, SOMOS TODOS DEMOCRATAS
}

\author{
WELCOME BACK, DEMOCRACY!*
}

\author{
Wendy Brown** \\ Tradução de Guaracy Bolívar Araújo Mendes Júnior ${ }^{* * *}$
}

Deduz-se do anterior que a vontade geral é sempre reta e tende sempre à utilidade pública, porém não se deduz que as deliberações do povo tenham sempre a mesma retidão.

(Jean-Jacques Rousseau - $O$ contrato social)

\section{A DEMOCRACIA COMO SIGNIFICANTE VAZIO}

Hoje em dia a democracia desfruta de uma popularidade mundial sem precedentes na história, porém nunca foi tão conceitualmente imprecisa e substancialmente vazia. Talvez a popularidade atual do termo dependa da imprecisão e esvaziamento de significado e eficácia como Barack Obama, é um significante vazio ao qual todos e cada um podem vincular seus sonhos e esperanças. Ou talvez o capitalismo, o gêmeo não idêntico da Democracia moderna e sempre o mais robusto e astuto dos dois, tenha reduzido a democracia a uma marca, essa última versão do fetichismo da mercadoria que separa por completo a imagem do produto a vender de seu conteúdo real ${ }^{1}$. Ou talvez, nessa ironia ao historicismo progressista na qual o século XXI apresenta deidades lutando numa intensidade que deveria ter sido vencida pela modernidade, a democracia emergiu como uma nova religião mundial - não uma forma específica de poder e cultura política, mas um altar ante o qual se ajoelha o Ocidente e seus admiradores, e através do qual os propósitos divinos das cruzadas imperiais são delineados e legitimados.

No mundo de hoje a democracia não apenas é exaltada em todo o mundo, mas também ao largo de todo o espectro político. Como nos regimes depois da Guerra Fria, quando os

\footnotetext{
* Título do artigo sobre a eleição de Obama em The Beaver, periódico da London School of Economics, 6 de novembro de 2008.

** Professora de Ciência Política estadunidense; leciona na Universidade da Califórnia, em Berkeley.

*** Mestre em Filosofia pela Universidade Federal de Minas Gerais. Doutorando em Filosofia pela Universidade Federal do Rio de Janeiro. Professor Assistente III da PUC Minas. E-mail: guaracyaraujo@gmail.com

${ }^{1}$ Patrick Ruffini nos lembra que grandes marcas "evocam sentimentos que não têm virtualmente nenhuma relação com os atributos do produto e suas especificações". Isso é tão verdadeiro para a Nike ou para a IBM quanto foi para Obama nas eleições norte-americanas de 2008. http://www.patrickruffini.com, 13 de fevereiro de 2008.
} 
outrora súditos soviéticos ainda festejam a bem-aventurança empreendedora, avatares do neoliberalismo e liberais obstinados, a esquerda euro-atlântica também se fascina pela marca. Saudamos a democracia por reparar o abandono da política de um Marx alheio às temáticas hegelianas (ou bem dizemos que a democracia radical era desde o início apenas o que se entende por comunismo), tentamos capturar a democracia mediante metas e ethoi inéditos, escrevemos "a democracia por vir", "a democracia dos não contados", "soberania democratizadora", "oficinas de democracia", "democracia pluralizante", etc. Berlusconi e Bush, Derrida e Balibar, comunistas italianos e Hamas, somos todos democratas hoje em dia. Porém, o que resta da democracia?

\section{O PODER DO DEMOS}

Não se pode enfatizar suficientemente: a democracia liberal, forma dominante da modernidade euro-atlântica, é apenas uma variante entre os meios de repartição do poder político conotado por este termo venerável do grego. Demos + cratie significa poder do povo em contraste com a aristocracia, a oligarquia, a tirania e também com a condição de colonizados ou ocupados. Porém nenhum argumento irrefutável poderia comprovar que a democracia implica inerentemente a existência da representação, constituições, deliberações, participação, liberdade de mercado, direitos, universalidade ou mesmo igualdade. O termo contém uma afirmação simples e puramente política: o povo se governa a si mesmo, é o todo e não uma parte nem um grande Outro que é politicamente soberano. Nesse sentido, a democracia é um princípio inconcluso - não especifica que poderes devem ser repartidos entre nós, nem como o poder do povo deve ser organizado, nem através de quais instituições ou condições suplementares deve ser estabelecido e assegurado. Desde o início, o pensamento ocidental da Democracia tem sido uma espécie de barganha. Dito de outra forma, mesmo que teóricos - desde Aristóteles, Rousseau, Tocqueville e Marx até Rawls e Wolin - sustentem (de modos diferentes) que a democracia necessita de condições precisas, enriquecimento, equilíbrios sutis, o termo em si não as estipula. Talvez essa seja outra razão pela qual o entusiasmo contemporâneo pela democracia nos permite ver tão facilmente até que ponto seu objeto foi esvaziado de conteúdo. 


\section{DESDEMOCRATIZAÇÃO}

Se é difícil determinar com segurança por que a democracia é tão popular hoje em dia, é mais fácil identificar os processos que reduzem mesmo a democracia liberal (parlamentar, burguesa ou constitucional) a uma casca do que era. Nas regiões do mundo que desde algum tempo têm navegado sob a bandeira democrática, como se deu que o povo não esteja de nenhuma forma governando em comum e para o comum? Que constelação das forças e fenômenos da modernidade tardia evisceraram a substância da já limitada democracia moderna?

Em primeiro lugar, ainda que desde muito tempo o poder corporativo eroda as esperanças e práticas do poder popular, esse processo alcançou um nível sem precedentes ${ }^{2}$. Não se trata simplesmente de grupos que compram (ou viram) políticos e modelam abertamente a política nacional e internacional, nem de que a mídia pró-corporativa que lhes pertence ridicularize a ideia da informação pública e da responsabilidade do poder. Mais que uma interferência, as grandes democracias são testemunhas de uma fusão do poder dos grupos e do poder do Estado: a transferência maciça das funções do Estado para o setor privado, desde as escolas a as prisões, passando pelo exército; banqueiros de negócios e CEO que se convertem em ministros ou chefes de gabinete; estados proprietários latentes com enorme capital financeiro e, acima de tudo, um poder estatal desavergonhadamente atraído pelo projeto de acumulação do capital através de sua política fiscal, ambiental, energética, social e monetária, para não mencionar o fluxo de assistência direta e apoio a todos os setores do capital. A população, o demos não é capaz de ver o que está por trás da maioria desses desenvolvimentos, e menos ainda de questioná-los, de se opor a eles e propor outros objetivos. Por não contar com recursos para desafiar as necessidades do capital, eles presenciam em geral passivamente o seu próprio abandono.

Em segundo lugar, até as eleições "livres", o ícone mais importante (e talvez superficial) da democracia, se transformaram em um circo de marketing e management, desde o espetáculo da obtenção dos fundos de campanha até a "mobilização" dirigida aos eleitores. À medida que os cidadãos estão submetidos a estratégias sofisticadas de marketing de campanhas eleitorais que tornam o voto equivalente à escolha de marcas de produtos eletrônicos, a vida política se reduz continuamente ao sucesso midiático e publicitário. Não

\footnotetext{
${ }^{2}$ Nenhum trabalho a esse respeito é superior ao livro de Sheldon S. Wolin, Democracy Inc. (Princeton: Princeton University, Press, 2008).
} 
são apenas os candidatos que são apresentados em uma embalagem elaborada por especialistas em relações públicas, que estão mais acostumadas a promover as marcas e a organizar as campanhas midiáticas dos grandes grupos do que a manejar os princípios democráticos; são também os programas e as agendas políticas que se vendem como bens de consumo e não como bens públicos. Não é de surpreender que haja cada vez mais CEO no governo, o que ocorre paralelamente ao crescimento dos departamentos universitários de ciências políticas, que recrutam docentes em escolas de administração e economia.

Em terceiro lugar, o neoliberalismo como racionalidade política lançou um assalto frontal contra os fundamentos da democracia liberal, deslocando seus princípios de constitucionalidade, igualdade diante da lei, liberdades políticas e civis, autonomia política e universalismo no rumo dos critérios do mercado: razões de custo-benefício, eficiência, rentabilidade e eficácia ${ }^{3}$. É através dessa racionalidade liberal que os direitos, o acesso à informação e outras proteções constitucionais bem como a transparência e a responsabilidade do governo, o respeito pelos procedimentos se desviam ou se deixam de lado com facilidade. Sobretudo, é dessa maneira que o Estado deixa de ser a encarnação da soberania do povo para converter-se em um operador de gestão de negócios ${ }^{4}$. A racionalidade neoliberal modela cada ser humano e instituição, incluindo o Estado constitucional, com base no modelo empresarial, e assim supera os princípios democráticos em prol de princípios empreendedoristas tanto na vida pública quanto na social. Além de destronar o demos da democracia, essa transformação permite a expansão do poder executivo do estado no mesmo momento em que declina a soberania estatal - retornaremos a este tema. Tendo reduzido a substância política da democracia a escombros, o neoliberalismo então surrupiou o termo para servir seus objetivos. Consequentemente a "democracia de mercado", antiga alusão depreciativa ao poder do capital desregulado, se converte na maneira cotidiana de descrever uma forma que já não tem nada a ver com o povo se governando.

Porém o capital e a racionalidade neoliberal não são os únicos agentes responsáveis pela decomposição das instituições, princípios e práticas da democracia liberal. Também se faz presente - este é o quarto ponto - a extensão do poder e domínio de ação dos tribunais,

\footnotetext{
${ }^{3}$ Para um tratamento mais extenso dos profundos efeitos desdemocratizantes da racionalidade neoliberal, sugiro o meu livro Les Habits neufs de la politique: Neoliberalisme et neoconservatisme, introdução de Laurent Jeanpierre (Paris: Les Praires Ordinaires, 2007).

${ }^{4}$ Ver as teses de Michel Foucault acerca da governamentalização do estado em "Society Must Be Defended": lectures at the College de France, 1975-76, traduzido por D. Macey (New York: St Martin's, 2003). (Nota do Tradutor: esse curso foi traduzido no Brasil com o título Em defesa da sociedade - São Paulo, Martins Fontes, 1999).
} 
nacionais e internacionais ${ }^{5}$. Uma variada gama de causas e lutas políticas, incluindo aquelas que têm suas raízes em movimentos sociais e campanhas internacionais pelos direitos do ser humano, se veem chamadas com cada vez mais frequência a comparecer diante dos tribunais, onde experts em direito fazem artimanhas e tergiversam com respeito a decisões políticas em uma linguagem tão complexa e misteriosa que apenas os juristas especializados no assunto a entendem. Ao mesmo tempo, os tribunais se reorientaram; já não decidem o que é proibido, mas sim o que se deve fazer - em resumo, passaram de uma função limitativa a uma função legislativa que efetivamente usurpa a tarefa clássica da política democrática ${ }^{6}$. Se o império da lei é um pilar importante de muitas formas de democracia, a governança dos tribunais constitui uma subversão dela. Tal governança inverte a subordinação crucial do poder judiciário ao poder legislativo, da qual depende a soberania popular, e outorga o poder político a uma instituição não representativa.

Em quinto lugar: ao lado da dominação da política pelo capital, da superação da racionalidade democrática pela racionalidade neoliberal e da juridificação da política, a erosão da soberania do Estado-Nação assim como o descolamento do poder soberano em relação aos Estados Nacionais é também crucial para a desdemocratização no Ocidente atual ${ }^{7}$. Se a soberania do Estado-Nação sempre envolveu certa ficção no que tange às aspirações desses estados à supremacia absoluta, à perfeição, à continuidade do direito, ao monopólio da violência, à perenidade, essa ficção era poderosa e forjou as relações internas e externas dos Estados Nacionais desde sua consagração em 1648 pelo Tratado de Westfalia. Porém, ao longo do último meio século, o monopólio desses atributos combinados pelo Estado-Nação foi gravemente comprometido pelo crescimento dos fluxos transnacionais de capitais, populações, ideias, recursos, produtos, violência e fidelidades políticas e religiosas. Esses fluxos destroem as fronteiras que atravessam e, uma vez dentro, se cristalizam para criar forças: dessa maneira a soberania do Estado-Nação se vê comprometida tanto em seus limites como em seu interior.

Quando os estados conservam uma brutal capacidade de atuar diante de sua soberania erodida, e quando se afastam do singular duplo sentido da soberania na democracia -

\footnotetext{
${ }^{5}$ Essa expansão é, em parte, devida a ativistas bem-intencionados que buscam vencer de todas as formas nas cortes, ainda que a democracia possa ser uma baixa inadvertida resultante de seu sucesso.

${ }^{6}$ Ver Gordon Silverstein, Law's Allure: How Law Shapes, Constrains, Saves and Kills Politics (New York: Cambridge University Press, 2009) e "Law as Politics/Politics as Law", dissertação em progresso de Jack Jackson, Departamento de Ciência Política, Universidade da California, Berkeley.

${ }^{7}$ Ver o meu artigo "Porous Sovereignty, Walled Democracy" a aparecer brevemente em La Revue internationale des livres et des idées.
} 
proveniente do povo e exercida por cima deste - isso implica duas consequências especialmente importantes. Por um lado a democracia perde sua forma e contornos politicamente necessários e, por outro, os estados abandonam qualquer pretensão de encarnar a soberania popular e de cumprir a vontade popular; um processo já iniciado pela racionalidade neoliberal, como já assinalamos aqui. Sobre o primeiro ponto, a democracia, governo do povo, somente é significativa e passível de exercício em um quadro claramente delimitado - é o que assinala o termo soberania na equação entre "soberania popular" e "democracia". A democracia sem território de jurisdição definido (no sentido virtual ou literal) é politicamente desprovida de sentido: para que o povo possa governar-se, deve existir uma entidade coletiva identificável na qual a repartição do poder é organizada e sobre a qual esse poder possa exercer-se. Certamente as grandes dimensões do Estado-Nação limitam desde o princípio as formas de repartir o poder que dão sentido à democracia, porém quando o próprio território jurídico é substituído por espaços pós-nacionais e transnacionais nos quais atuam os poderes político, econômico e social, a democracia se torna incoerente.

Sobre o segundo ponto: os estados desprovidos de soberania se convertem em estados delinquentes, tanto em seus assuntos internos quanto externos. O ponto de referência para os exercícios ordinários do poder não é nem a representação do Povo nem a sua proteção - (esta última sendo a justificação do poder do Estado no liberalismo clássico). Para os Estados contemporâneos, em um eco distante da raison d'etat do velho realismo, trata-se de substituir a busca do prestígio do poder por um complexo papel duplo enquanto atores inseridos, facilitadores e estabilizadores da globalização econômica. Nesse contexto, o povo se reduz a um conjunto de pequenos acionistas passivos de estados governamentalizados que operam internamente como empresas e como débeis gerentes de uma ordem externa e global do capital. O que se tornou gritantemente visível na resposta dada pelos estados à crise do capital financeiro de Outono de 2008.

Por fim, a securitização constitui outra e importante parcela da ação estatal desdemocratizadora efetuada pelos estados ocidentais no mundo globalizado da modernidade tardia. O conjunto das ações estatais destinadas a prevenir e desviar o terrorismo em países tão diferentes como Israel, Grã-Bretanha, Índia ou Estados Unidos são por vezes caracterizados erroneamente como um ressurgimento da soberania estatal; mas, assim como resgates estatais dos prejuízos do capital, são de fato signos do desengajamento do Estado de seu poder soberano e tem tudo a ver com essa perda de soberania. 
Favorecido pelo afastamento neoliberal diante dos princípios liberais (liberdade, igualdade, império da lei) rumo a uma ênfase nos custos, benefícios e eficácia, o estado de segurança responde à debilitação e à disputa de sua soberania por uma série de medidas inadvertidamente desdemocratizadoras - da suspensão dos direitos de movimento e informação à atribuição de etiquetas raciais, ao crescimento das zonas de segredo do Estado e de guerras permanentes não declaradas.

Resumindo tudo, para que as pessoas possam governar-se a si mesmas, elas devem constituir um povo que tenha acesso aos poderes que buscam democratizar. A erosão da soberania do Estado-Nação pela globalização destruía a primeira dessas condições, e o neoliberalismo, ao desencadear o poder do Capital como um poder mundial desenfreado, elimina a segunda. Porém, se a "democracia real” se encontra em um estado deplorável, para mudar tal situação é necessário examinar o que resta do princípio e ideal da democracia em nossos tempos, se é que algo restou.

\section{OS PARADOXOS DEMOCRÁTICOS}

É um fato bem difundido que a democracia ateniense excluía de suas listas a maior parte da população da Ática - as mulheres, os escravos, os estrangeiros e outros que não reuniam as condições de linhagem necessárias para serem cidadãos. Essas exclusões no funil da Democracia eram extremas, mas não excepcionais. A democracia como conceito e como prática ainda se encontrava rodeada de uma zona periférica não democrática, e ainda tinha um substrato interno não incorporado que ao mesmo tempo a mantinha materialmente e que também lhe servia para se definir por oposição. Historicamente, todas as democracias definiram um grupo interno excluído - que pode ser composto de escravos, indígenas, mulheres, pobres ou, hoje em dia, imigrantes estrangeiros em situação irregular, ou pode pertencer a determinadas raças e etnias ou religiões. Ainda existe um mundo exterior que permite que a democracia se defina: os "Bárbaros", nome dado pelos antigos que foi atualizado de diversas formas desde aquela época, desde o comunismo até as colônias das próprias democracias. Em nossa época a figura do "islamismo" reconforta os democratas por desfrutar dessa condição, ainda (e talvez especialmente) no contexto da desdemocratização do Ocidente. Ainda existe um antiuniversalismo visível no coração da democracia, o que sugere que se o sonho imperial de uma democracia universal se fizesse realidade, não assumiria a forma da democracia. 
Se a democracia pré-moderna e republicana se baseou na ideia de exercer o poder em forma comum - o poder do povo para o povo -, e se por conseguinte se centrou em um princípio de igualdade, a promessa da democracia moderna sempre foi a liberdade. A democracia moderna nunca advogou pela igualdade, com a exceção dos sentidos mais formais da representação (uma pessoa - um voto) ou da igualdade diante da lei (que não é uma derivação necessária da democracia, raramente é assegurada na prática e é irrelevante para uma igualdade substancial). Antes, é a difícil aposta de Rousseau - que renunciemos à nossa liberdade individual não governada em prol do poder político coletivo de modo a tornar concreta a nossa liberdade individual - que está no coração da supremacia normativa reivindicada pela democracia. De fato, a liberdade individual é a metonímia mais poderosa relacionada com a democracia, enquanto que a promessa de governo pelo povo frequentemente é esquecida ${ }^{8}$. Apenas a democracia pode nos fazer livres, já que apenas em uma democracia nós autorizamos os poderes que nos governam.

Na Modernidade, a liberdade entendida como autolegislação é suposta como desejo universal do ser humano, ou mesmo (para Kant, Rousseau e Stuart Mill) como a quintessência do que é ser humano. De fato, é o nascimento, com a Modernidade, do sujeito moral livre a priori que estabelece a democracia como a única forma política legítima do Ocidente. Essa figura do sujeito que continua brindando à democracia com legitimidade incontestável. Porém, ao mesmo tempo, o rosto branco, masculino e colonial desse sujeito permitiu e perpetuou as hierarquias, as exclusões e a violência que marcaram a democracia em toda a sua existência moderna. Portanto, existe uma não liberdade evidente e talvez necessária no coração da democracia, sugerindo que, se o sonho imperial de tornar todas as pessoas livres se materializasse, não assumiria a forma da democracia.

\section{A IMPOSSIBILIDADE DA LIBERDADE}

A presunção normativa da democracia moderna é a autolegislação obtida ao repartir o poder de governar: a soberania do sujeito está vinculada à soberania do regime, e uma garante a outra. Porém, legislação de quê, poder de quê? Na Modernidade Tardia, a reflexão teórica sobre uma série de poderes normativos (formalmente não políticos) combinada com as

\footnotetext{
${ }^{8}$ De fato, essa é a premissa que mesmo Hobbes luta para abonar em seus fabulosos ardis semânticos em torno dos termos autor, autoria e autoridade, através dos quais ele tenta nos tornar autores do absolutismo de Estado que nos domina.
} 
críticas devastadoras ao sujeito kantiano tornou a noção de liberdade particularmente complexa e esquiva. Que poderes devemos exercer, sobre que devemos legislar em conjunto, que forças devemos submeter a nossas vontades para poder dizer, mesmo modestamente, que governamos a nós mesmos, que nós mesmos legislamos? As respostas a essas perguntas dividem os democratas desde muito tempo. Por um lado, os liberais tratam a representação eleitoral legislativa como o centro da questão, associando-lhe limites claros relativos às transgressões individuais em termos de ações e fins. Por outro lado, os marxistas afirmam que a primeira condição da liberdade humana é que os meios de existência sejam propriedade da coletividade. Os democratas radicais insistem na participação direta na política, enquanto os libertarianos buscam reduzir o poder e as instituições políticas.

Uma vez abandonada a empáfia do sujeito moral a priori para avaliar esta panóplia de poderes sociais e discursos que nos constroem e conduzem, é impossível sentir entusiasmo pela formulação liberal. O consentimento popular em relação às leis e aos legisladores não é suficiente para cumprir a promessa democrática de autolegislação. É preciso entender e controlar as múltiplas forças que nos constroem como sujeitos, que produzem as normas mediante as quais percebemos a realidade e julgamos o bem e o mal, e que nos apresentam as opções que temos à nossa frente ao votar e legislar. $\mathrm{O}$ poder entendido como fabricação do mundo e não só como a dominação sobre ele - ou melhor, a dominação como fabricação do sujeito e não como simples poder repressivo-, exige que os democratas realizem uma prospecção em ordens polivalentes que apodere as bases da liberdade. A simples ideia de que poderes que estão fora de nosso alcance e controle estão permanentemente construindo o mundo social e a nós mesmos arruína a noção liberal de autolegislação pelo voto e consentimento geral. E ainda assim a ideia de dirigir democraticamente todos os poderes que nos constroem é absurda: equivale avançar sem ajuda, ou compreender desde o exterior os elementos psíquicos que modelam nossa concepção do mundo. Para que tenha sentido, a democracia deve submergir mais fundo do que nunca naquilo que fabrica esse poder e, para falar a verdade, deve abandonar a liberdade como troféu. Desde essa perspectiva, a democracia nunca pode ser realizada: é uma meta (inalcançável), um projeto político em constante evolução; a democratização exige de seus partidários que lutem pela repartição de poderes que lhes dão forma e lhes governam, mas esse é um processo sem fim ${ }^{9}$.

\footnotetext{
${ }^{9}$ Sheldon Wolin elabora esse ponto de modo ligeiramente diferente, propondo que apenas o que ele nomeia “democracia fugitiva” é possível, ou seja: expressões episódicas por parte do povo de seus direitos consagrados.
} 
Tão perturbadora para a formulação liberal como as concepções foucaultianas e derridianas acerca de modalidades de poder para além da lei e do comando, está a capacidade do capital de produzir e organizar os sujeitos democráticos. O que significa poder democrático se a economia está desatrelada do político e até mesmo o domina? Porém, o que poderia ser mais fantasioso que a ideia de subordinar uma economia globalizada - e sua capacidade de formar a vida social, política, cultural, ecológica - ao governo político democrático, ou mesmo a qualquer tipo de governo político?

Em suma, além do poder do Estado, cabe levar em conta o capital e uma série de poderes normativos menos expressamente econômicos ao considerarmos as perspectivas atuais de uma redemocratização. A História não oferece nenhuma experiência exitosa de democratização desses poderes. Para a continuidade da crença na democracia política como a realização da liberdade humana, é preciso literalmente resguardar nosso olhar diante de poderes que estão imunizados contra a democratização, que negam a autonomia e a primazia do político das quais dependem a teoria da democracia no passado e no presente ${ }^{10}$. Alternativamente, essa crença nos propõe que pensemos e pratiquemos a democracia com um olhar realista posto nos poderes que a democracia nunca tentou teorizar, contradizer ou superar $^{11}$. Esta segunda possibilidade propõe uma ampla e dificilmente imaginável ruptura para com o monopólio liberal sobre o termo democracia.

\section{OS SERES HUMANOS QUEREM A LIBERDADE? QUEREMOS QUE OS SERES HUMANOS SEJAM LIVRES?}

Existe um desafio final para aqueles que acreditam no poder do povo, talvez o mais grave de todos. Como dissemos, pressupor que a democracia é um bem implica a pressuposição de que os seres humanos querem viver sob suas próprias leis, e que o governo do demos freia o risco de um poder político concentrado e não fiscalizado. Porém, hoje em dia, que prova histórica ou preceito filosófico nos permite afirmar que os seres humanos querem, como disse Dostoiévski, "a liberdade mais do que o pão"? Todas as indicações do

\footnotetext{
${ }^{10}$ Para um desenvolvimento mais pleno desse ponto, ver os meus artigos "Sovereign Hesitations", no livro organizado por Pheng Cheah e Suzanne Guerlac, Derrida and the Time of the Political (Durham: Duke University Press, 2008), e "The Return of the Repressed: Sovereignty, Capital, Theology" no volume organizado por David Campbell e Morton Schoolman: The New Pluralism: William Connolly and the Contemporary Global Condition (Durham: Duke University Press, 2008).

${ }^{11}$ Para uma discussão mais completa acerca dos filósofos pós-marxistas que perseguem a possibilidade de tornar a economia novamente subordinada à esfera política democrática, ver o meu artigo "The Return of the Repressed".
} 
que se passou ao longo do último século nos mostram que entre as seduções do mercado, as normas do poder disciplinar e a insegurança vinculada como a geografia humana cada vez mais fluida e desordenada, a maioria dos ocidentais preferiu a moralização, o consumo, o conformismo, o prazer, a luta, e que se lhes diga o que devem ser, pensar e fazer para serem os autores de suas próprias vidas. Esse foi o desafio para o futuro da emancipação projetado por Herbert Marcuse no meio do século $\mathrm{XX}^{12}$. E se os seres humanos rechaçam a responsabilidade da liberdade, e não são nem educados e nem encorajados para o projeto da liberdade política, o que isso significa para os sistemas políticos que assumem como suposto esse desejo e orientação? Que extrema vulnerabilidade à manipulação pelos poderosos e dominação por forças sociais e econômicas é implicada por essa condição? Platão temia que almas desordenadas encarregadas de sua própria existência política poderiam acarretar decadência e licenciosidade sem freios, mas existe um perigo mais visível e preocupante hoje: o fascismo autorizado pelo povo. Quando os não democratas se alojam nas brechas da democracia, pressionados pelo medo e pela ansiedade diante de um panorama global cada vez mais limitado, ignorando os poderes que os acossam: como se pode pretender que votem e lutem por sua própria liberdade e igualdade, e ainda pela dos outros?

E assim encaramos por um lado os problemas gerados por aqueles que não aspiram à liberdade democrática, e por outro lado os das democracias que não queremos - pessoas "livres" que possibilitam o poder de teocracias, impérios, atrozes sistemas de limpeza étnica, comunidades fechadas, sociedades estratificadas por origem étnica e condição de imigrante, constelações pós-nacionais do neoliberalismo agressivo, ou tecnocracias que prometem curar os males sociais driblando os processos e as instituições democráticas.

Evitar essas duas possibilidades é o problema de quem põe sua própria satisfação de curto prazo acima da conservação do planeta, que dá mais valor à segurança ilusória do que à paz, e que não tem nem a menor inclinação por sacrificar seus prazeres ou suas aversões pelo bem coletivo.

Rousseau atribuiu tamanho peso à dificuldade de conduzir uma população corrompida para a vida pública que se considera que sua defesa da democracia desmonta a si mesma enquanto projeto para transformar um povo corrupto em um povo de democratas. Existem muitas maneiras de entender o que ele queria dizer por "obrigar alguém a ser livre", mas todas convergem na suposição de que a imposição desse compromisso é autocontraditória. De toda

\footnotetext{
${ }^{12}$ Herbert Marcuse, One Dimensional Man (New York: Beacon, 1964). (Nota do tradutor: obra traduzida no Brasil. A saber: A ideologia da sociedade industrial - Rio de Janeiro: Zahar, 1967).
} 
forma, é difícil imaginar na atualidade o que poderia compelir os seres humanos à tarefa de governar a si mesmos ou contestar de forma exitosa os poderes que os dominam.

\section{POSSIBILIDADES}

A figura desengonçada do governo popular na contemporaneidade deve servir como fator adicional para que as esquerdas abandonem as lutas pela democracia e se engajem num esforço imaginativo em prol de novas formas políticas? Ou, ao invés disso, exige uma apreciação sóbria da democracia como um grande ideal que nunca se materializará? Temos de afirmar que a democracia (como a liberdade, a paz e a felicidade) nunca foi viável, e que serve (mas: poderá continuar servindo?) como escudo contra uma concepção completamente sinistra da coletividade humana? Ou talvez a democracia, assim como a emancipação, apenas se possa tornar concreta como protesto e, especialmente na atualidade, devesse ser formalmente rebaixada de uma forma de governo à condição de uma política de resistência.

Minha incerteza aqui é real. Mas estou segura de que este não é o momento para lançar slogans que deslocam o olhar dos poderes que destroem as condições da democracia na atualidade. O ardor dos filósofos e ativistas de esquerda por "aprofundar a democracia", “democratizar a democracia", "restaurar a democracia", "pluralizar a democracia”, ou apostar na "democracia por vir..." só pode ser útil quando considera esses poderes diretamente. Precisamos de deliberações honestas e profundas a respeito do que constitui um limite mínimo para a distribuição do poder democrático; se e por que continuamos a acreditar na democracia; se é uma forma viável no século XXI, e se existem alternativas não aterrorizantes que possam ser mais eficazes para debelar a obscuridade. Existe um caminho para atingir os poderes que o povo deve controlar para que possamos considerar, modestamente, que legislamos sobre nós mesmos? A liberdade que promete a democracia é algo que os seres humanos desejam - ou que se possa lhes ensinar a querer de novo? Essa liberdade faz bem para o mundo?

De que tipo de contenções e limites a democracia necessita? Se estes se encontram fora de alcance, a democracia é possível? E, se conseguirmos responder a todas estas perguntas, resta a mais difícil: como pode o demos identificar e adquirir os poderes a serem exercidos em conjunto, para que a democracia não se reduza a uma mera máscara que legitima sua própria inversão? 